\title{
Effect of Electric Pulse Treatment on the Corrosion Resistance of HAl52-2 Aluminum Brass
}

\author{
Zuo-fu Zhao ${ }^{*}{ }^{*}$, Xin Li ${ }^{a}$, Dong-dong Shan ${ }^{a}$,Jing-gang Qi ${ }^{a}$, Bing Wang ${ }^{a}$, Liang Liu ${ }^{a}$, Xiaobo Ma \\ ${ }^{a}$ School of Material Science and Engineering, Liaoning University of Technology, Jinzhou 121001, China \\ ${ }^{b}$ School of Material Science and Engineering, Inner Mongolia University Of Technology, Hohhot, 010000, China
}

Received: September 29, 2017; Revised: November 19, 2018; Accepted: June 25, 2019

\begin{abstract}
In this work, the effects of electric pulse treatment (EPT) on the corrosion resistance of HA152-2 aluminum brass has been investigated using electrochemical workstation, scanning electron microscope and X-ray diffraction. The results have shown that after EPT, the corrosion potential increased and the corrosion current density decreased. At the same time, the diameter of the capacitive reactance arc of the HAl52-2 aluminum brass after EPT was $5 \sim 6$ times of the original sample, and the thickness of dezincification layer was reduced from $59.2 \mu \mathrm{m}$ to $50.2 \mu \mathrm{m}$ by $84.8 \%$. The aluminum brass alloy with EPT has demonstrated better corrosion resistance of than the original sample.
\end{abstract}

Keywords: corrosion behavior, electric pulse treatment, $\gamma$ phase, HAl52-2 aluminum brass.

Due to the excellent thermal conductivity and corrosion resistance, Aluminum brass has been widely used in power plant and heat exchange material, such as the condenser tube ${ }^{1}$. It has attracted much attention from the researchers in the world on how to further improve the corrosion resistance and to eliminate the potential safety hazard of aluminum brass in industrial production where complex environment and serious corrosion presents. The literature has shown that the addition of elements $\mathrm{As}, \mathrm{Ce}, \mathrm{B}, \mathrm{Co}$ and $\mathrm{Cr}$ to the aluminum brass can reduce the grain size and the corrosion rate, and can inhibit the dezincification ${ }^{2-4}$. However, the reuse of aluminum brass will be obstructed, and the surrounding environment will be polluted due to the toxicity of As element. On the other hand, the corrosion resistance of aluminum brass cannot be improved obviously for varying environments and water qualities, and the element $\mathrm{Cr}$ may even reduce the corrosion resistance in $\mathrm{NH}_{4} \mathrm{Cl}$ environment by the trace elements of $\mathrm{Cr}^{5-7}$.

As a new material processing method, EPT has attracted much research attention in recent years. Many experimental results have shown that by EPT, the nucleation rate can be efficiently-improved, the solidification structure of the metals can be refined and the segregation of alloying elements can be controlled, where the comprehensive performance of alloys was then improved ${ }^{8-13}$. Meanwhile, it has been reported that the morphology, size and distribution of $\gamma$ phase and the comprehensive performance of silicon brass can also be ameliorated by $\mathrm{EPT}^{14}$. In this work, the corrosion behavior of HAl52-2 aluminum brass as well as the corresponding micro-mechanisms of the corrosion resistance with and without EPT has been examined by many research methods, such as the electrochemical workstation and the scanning electron microscope, providing theoretical support to the research of the corrosion resistance of aluminum brass.

*email: zzf197810089927@163.com

\section{Experiment Materials and Methods}

HAl52-2 aluminum brass (Cu: 52wt\%, Al: 2wt\%, Zn: bar.) block (dimensions: diameter $10 \mathrm{~mm}$, height $10 \mathrm{~mm}$ ) was used for the present study. Firstly, the specimen was preheated to 400 ${ }^{\circ} \mathrm{C}$, and the temperature of the furnace with silicon carbide rods was heated to $1150^{\circ} \mathrm{C}$. When $\mathrm{Cu}$ and $\mathrm{Al}$ were melted, $\mathrm{Zn}$ was pressed to the melt by a bell jar for 5 minutes. The melt was then poured into a permanent mold, and after solidification, the original samples were obtained. The graphite electrode was inserted vertically into the alloy melt with $3 \mathrm{~cm}$ in depth. The electric pulse frequency was $15 \mathrm{~Hz}$, and the pulse voltages were $500 \mathrm{~V}$ and $700 \mathrm{~V}$, respectively, and the treatment time was 30 $\mathrm{s}$. The samples were sealed by epoxy resin in a size of $10 \mathrm{~mm}$ $\times 10 \mathrm{~mm}$. The samples for corrosion test were prepared, after polished, degreased by ethanol and ultrasonic cleaned SEM. IVIUM electrochemical workstation and D/max-2500/PC X-ray diffractometer were used to examine the samples.

The polarization curve and EIS AC impedance spectroscopy of the samples with and without EPT were tested in $3.5 \% \mathrm{NaCl}$ solution by an IVIUM electrochemical workstation corrosion resistance test system. The platinum was used as the auxiliary electrode with $1 \mathrm{~cm} \times 1 \mathrm{~cm}$ in size. The reference electrode was standard calomel electrode (SCE). The scan speed was $0.5 \mathrm{mV} / \mathrm{s}$ and the open circuit potential was in the range from $-250 \mathrm{mV}$ to $1000 \mathrm{mV}$ in the polarization curve tests. The sinewave amplitude modulation was $10 \mathrm{mV}$ and the frequency was $100 \mathrm{KHz}-0.01 \mathrm{~Hz}$ in EIS AC impedance spectroscopy testing.

\section{Results and Discussion}

\subsection{The effect of microstructure and property of HAl52-2 aluminum brass by EPT}

The metallographic microstructure of the samples was observed by a scanning electron microscope and a ZEISS 
Axiovert2000MAT metallurgical microscope, and the results are presented in Figure 1. It can be found that coarse grains are observed in sample (a) without EPT, where the $\gamma$ phase is starshaped and distributed aggregately on the grain boundary; the grain size of sample (b) with $500 \mathrm{~V}$ EPT and the $\gamma$ phase has decreased and dispersed; the grain size of sample (c) with $700 \mathrm{~V}$ EPT has decreased more obviously, and the $\gamma$ phase has changed into chunk-shaped on the $\beta$ phase boundary and grains. Based on above, the problem of segregation was solved efficiently.

The microhardness of the samples was tested using an HVS-1000 microhardness tester. The volume fraction of the $\gamma$ phase was measured and calculated, as shown in Figure 2. It can be seen that the $\gamma$ phase of the samples with EPT spreads into the matrix in solution treatment. The volume fraction decreased and the microhardness was obviously improved.

\subsection{The effect of corrosion resistance of HAl52-2 aluminum brass by EPT}

The electrochemical corrosion of the samples was tested using an IVIUM electrochemical workstation and the steadystate polarization curves of samples were given in Figure 3. It can be seen that the polarization curve of cathode is smooth, while the polarization curve of anode is flat, suggesting smaller electrode reaction and resistance of the polarizability. Two characteristic regions, the active dissolution region and the transition region of active deactivation, are presented in the polarization curve of cathode of all the three samples. The free corrosion potential of samples with EPT is higher than that without EPT, and the corrosion current density of samples with EPT is lower, implying that the ability of passivation of the samples with EPT was improved obviously.

The polarization curve tested in the experiment was simulated with Tafel curve extrapolation by CorrView Version 3.0 simulation software, and the parameters for the corrosion test are listed in the Table 1.

Based on Figure 3 and Table 1, the free corrosion potential of aluminum brass samples increased by $1 \%$ from $-0.26602 \mathrm{~V}$ without EPT to $-0.23969 \mathrm{~V}$ with EPT, and the corrosion current density decreased from $9.5110 \times 10^{-6}$ $\mathrm{A} \cdot \mathrm{cm}^{-2}$ to $1.3892 \times 10^{-7} \mathrm{~A} \cdot \mathrm{cm}^{-2}$ by two magnitude orders.

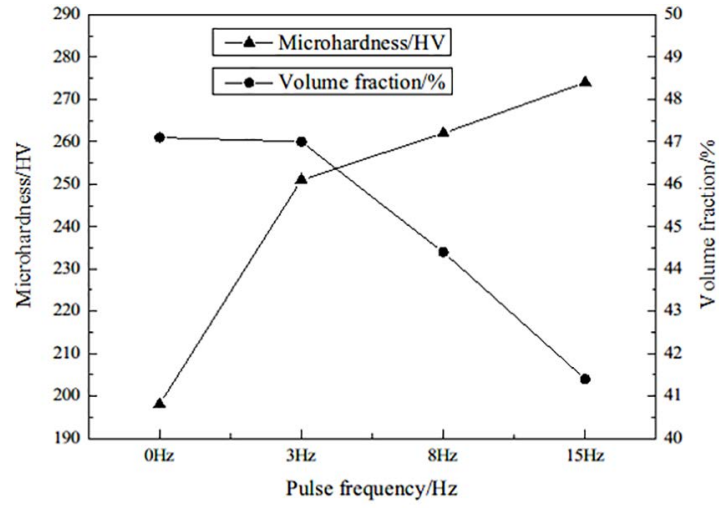

Figure 2. Performance comparison of aluminum brass alloy

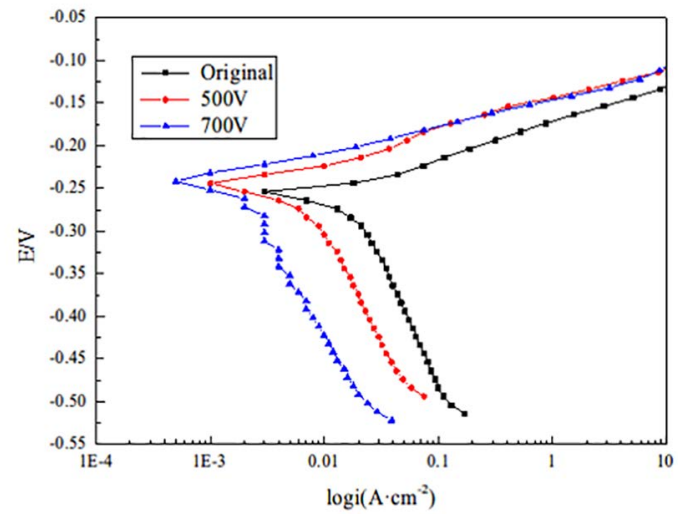

Figure 3. Polarization curves of aluminum brass alloy

Table 1. Related parameters of polarization curves of silicon brass alloy with and without EPT in $3.5 \% \mathrm{NaCl}$

\begin{tabular}{ccc}
\hline Corrosion samples & $\begin{array}{c}\text { Free corrosion } \\
\text { potential }\left(\mathrm{E}_{\text {corr }} / \mathrm{V}\right)\end{array}$ & $\begin{array}{c}\text { Free corrosion } \\
\text { current density } \\
\left(\mathrm{i}_{\text {corr }} / \mathrm{A} \cdot \mathrm{cm}^{-2}\right)\end{array}$ \\
\hline Without EPT & -0.26602 & $9.5110 \times 10^{-6}$ \\
EPT(500V) & -0.24953 & $8.5659 \times 10^{-7}$ \\
EPT(700V) & -0.23969 & $1.3892 \times 10^{-7}$ \\
\hline
\end{tabular}

It can then be concluded that the corrosion resistance of aluminum brass alloy has been significantly increased.
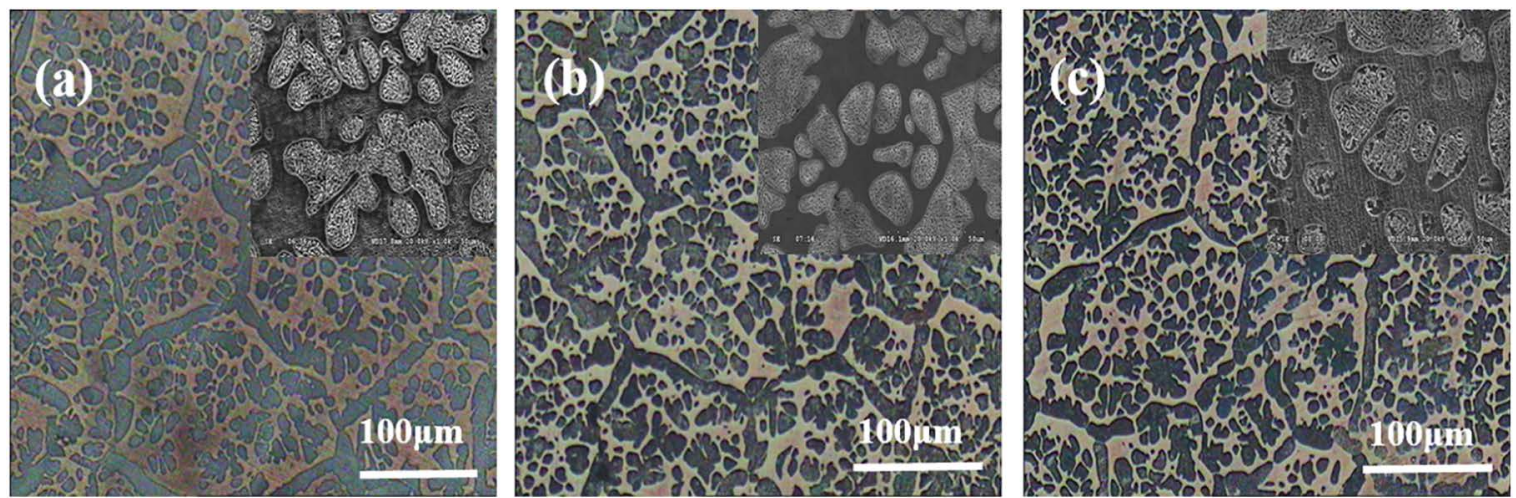

Figure 1. Microstructure of aluminum brass alloy with and without EPT (a) Original sample (b) $500 \mathrm{~V}$ (c) $700 \mathrm{~V}$ 


\subsection{The effect of AC impedance spectroscopy of HAl52-2 aluminum brass by EPT}

The samples were tested using an IVIUM electrochemical workstation with a sine-wave amplitude modulation of 10 $\mathrm{mV}$ and a frequency of $100 \mathrm{KHz}-0.01 \mathrm{~Hz}$. The EIS AC impedance spectroscopy tested in the experiment is shown in Figure 4. It can be found that different features were formed in the Nyquist graph of the samples with and without EPT. After EPT, the solid solubility of Al was increased, and $\mathrm{Al}_{2} \mathrm{O}_{3}$ oxide film was formed on the surface of the samples. The diffusion of $\mathrm{Cu}$ and $\mathrm{Zn}$ atom was then blocked and the mass transfer rate was smaller than the formation rate of corrosion products. The mass transfer process was then obstructed, resulting from that the corrosion product layer was formed due to the gradual deposition of corrosion products on the surface of samples ${ }^{15-18}$. A bigger diameter of the capacitive reactance arc is usually related to a better corrosion resistance of the samples. After EPT, the diameter of capacitive reactance arc increased by 4-5 times from 365.0 to $2020.0 \mu \mathrm{m}$, suggesting the enhancement of the corrosion resistance of the aluminum brass with EPT.

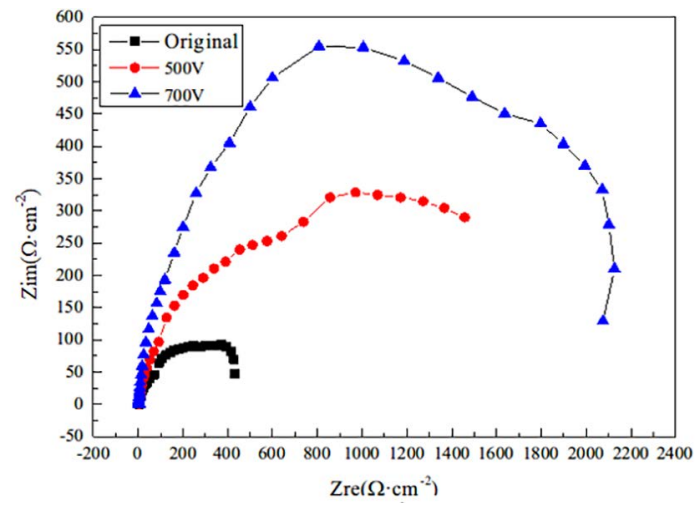

Figure 4. Nyquist pots of aluminum brass alloy in $3.5 \% \mathrm{NaCl}$

\subsection{The effect of morphology and thickness of dezincification of aluminum brass by EPT}

The samples were scanned using an S-3000N scanning electron microscope. The distribution of elements on electrochemical corrosion surface of HAl52-2 aluminum brass samples was detected, and the results are given in Figure 5

It has shown that $\mathrm{Zn}$ distributed heterogeneity on the corrosion surface of the original samples, while the relative $\mathrm{Zn}$ content increased and the relative $\mathrm{Cu}$ content decreased after EPT.

Figure 6 gives the corrosion morphology of electrochemical corrosion section of the aluminium brass samples. The thicknesses of dezincification layer of the aluminium brass samples were compared, as shown in Figure 7. From Figure 6 and Figure 7, it can be found that the dezincification layer of the original aluminium brass samples was porous (Fig. 6a) and the depth was up to $59.2 \mu \mathrm{m}$. The thickness of the dezincification layer with EPT decreased obviously by $90 \%$ at $53.3 \mu \mathrm{m}$ with $500 \mathrm{~V}$ EPT. For the samples with 700V EPT (Fig. 6c), it decreased by $84.8 \%$ at $50.2 \mu \mathrm{m}$, and the surface of matrix was covered tightly and uniformly. It can then be concluded that the re-corrosion of matrix was prevented, and the corrosion resistance of aluminium brass was efficiently improved.

\subsection{The mechanism analysis of the corrosion resistance of HAl52-2 aluminum brass alloys by $E P T$}

The preferential dissolution and resolution deposit mechanism, the double-space mechanism and the seepage mechanism were studied as the main mechanisms of dezincification corrosion ${ }^{19}$. The double-space mechanism and the seepage mechanism were combined by Jihui Wang $^{20}$, and the mechanism of seepage channel was explained by the crystal models of alloys. The double-space was formed during the corrosion process of brass and the resultant selective dissolution of $\mathrm{Zn}$ has also been proved.
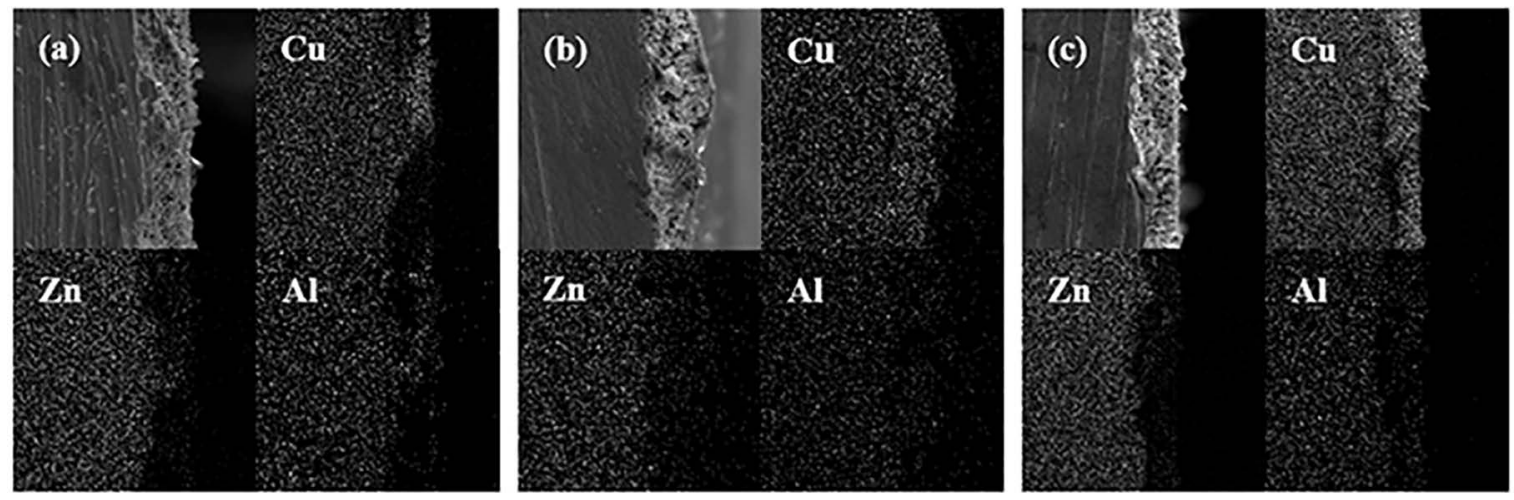

Figure 5. The elements distribution character of corroded surface of aluminum brass alloy with and without EPT (a) Original Sample (b) $500 \mathrm{~V}$ (c) $700 \mathrm{~V}$ 

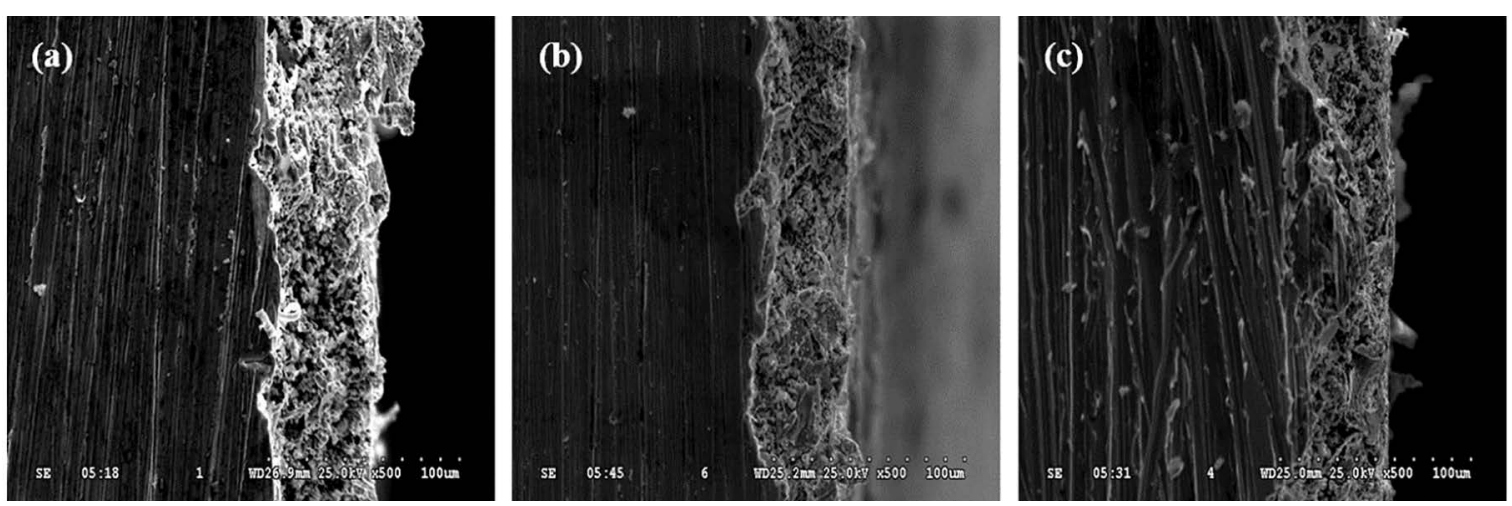

Figure 6. The morphology of dezincification of aluminum brass alloy (a) Original Sample (b) $500 \mathrm{~V}$ (c) $700 \mathrm{~V}$

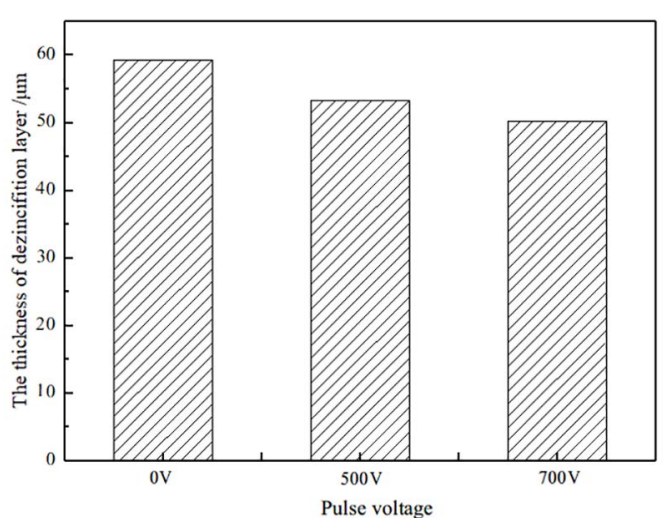

Figure 7. The thickness of dezincification layer of aluminum brass alloy

The XRD analysis of the phase structure of samples with and without EPT is given in Figure 8 and Figure 9, respectively, to further explore the internal relations between the changes of the corrosion resistance and phase structures.

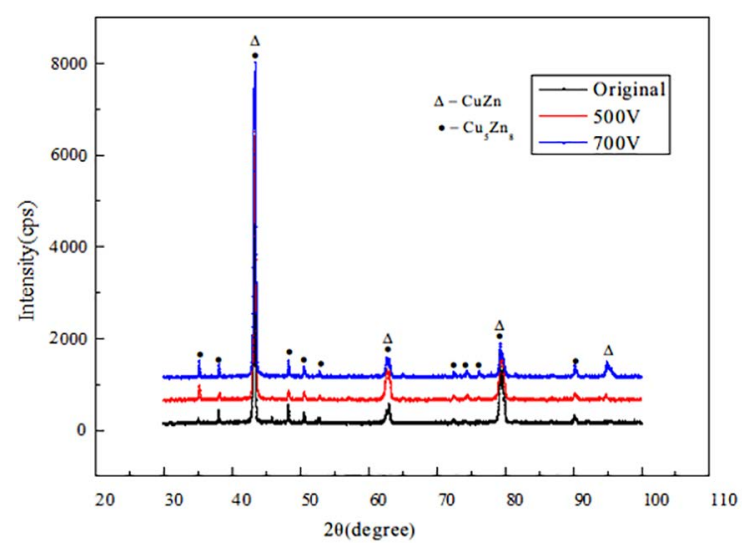

Figure 8. The XRD analysis of the phase structure of samples without corrosion

It can be concluded from the Figure 8 and Figure 9 that the $\mathrm{CuZn}$ and $\mathrm{Cu}_{5} \mathrm{Zn}_{8}$ phases were discovered in the samples without corrosion. $\mathrm{Zn}$ atom was dissolved and the $\mathrm{Cu}_{2} \mathrm{O}$ and $\mathrm{Cu}$ phases were formed during the corrosion process.

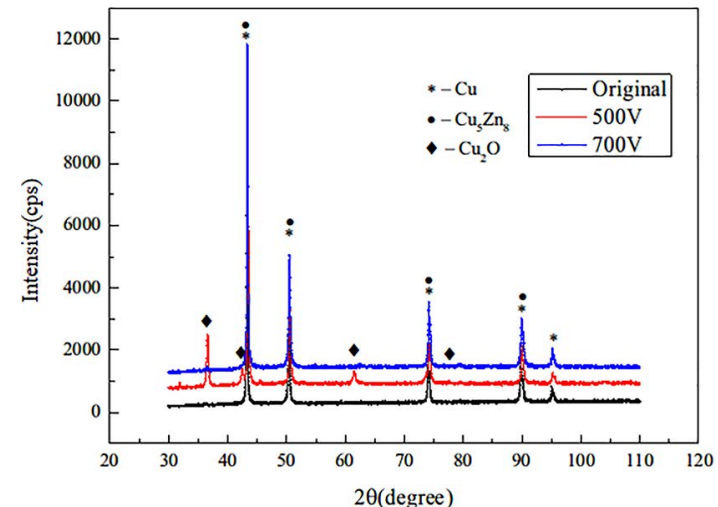

Figure 9. The XRD analysis of the phase structure of samples with corrosion

The findings show that dezincification occurred on the phase boundary between $\beta$ and $\gamma$ phases in the corrosion of aluminium brass alloys, and the $\beta$ phase was then corroded as anode. The corrosion of the $\gamma$ phase did not occur until the porous shape was formed on the corrosion layer ${ }^{21}$. The nucleation rate of the aluminium brass alloy melt was obviously improved and the problem of segregation was solved efficiently by EPT. Therefore, the $\mathrm{Zn}$ atom was uniformly distributed in the grains and the quantity of galvanic couple was decreased. The dezincification progress was then inhibited efficiently by EPT. The undercooling of aluminium brass alloy melt was improved by EPT, thus the size of atomic cluster decreased and the quantity increased. Additionally, the critical dimension of nucleation decreased during the nucleation process. The morphology, size and distribution of $\gamma$ phase can be ameliorated by EPT, and the rate of dezincification was decreased obviously.

\section{Conclusions}

1. The free corrosion potential of samples with EPT was higher than that in the samples without EPT, and the corrosion current density decreased from $9.5110 \times 10^{-6}$ $\mathrm{A} \cdot \mathrm{cm}^{-2}$ to $1.3892 \times 10^{-7} \mathrm{~A} \cdot \mathrm{cm}^{-2}$ by two magnitude orders. 
2. After EPT, the thickness of dezincification layer with EPT decreased from $59.2 \mu \mathrm{m}$ to $50.2 \mu \mathrm{m}$. The continuous and pelletized corrosion products were uniformly distributed on the surfaces of the samples. The diffusion of $\mathrm{Zn}$ atom was blocked, and the corrosion resistance of aluminium brass was significantly improved.

3. The volume fraction of $\gamma$ phase in the solidification structure of aluminium brass decreased by $0.12 \%$. The microhardness increased by $40 \%$ from 198 HV without EPT to $274 \mathrm{HV}$ with $700 \mathrm{~V}$ EPT. The average grain size decreased by $50 \%$ at $221.3 \mu \mathrm{m}$. The diameter of capacitive reactance arc increased by $4 \sim 5$ times from $365.0 \mu \mathrm{m}$ without EPT to 2020.0 $\mu \mathrm{m}$ with EPT. The optimum parameters for EPT were determined as $700 \mathrm{~V}, 15 \mathrm{~Hz}$, and $30 \mathrm{~s}$.

\section{References}

1. Zhang Juan. Effect of trace element on the corrosion resistance of Aluminium brass[D]. ChangSha: Central South University; 2008.

2. Wang Z, Jin S, Ye Y, Chen W, Pan S. The Study on Dezincification Corrosion Resistance of Hal77-2 Aluminium Brass. Materials Review B. 2016;30(8):84-87, 99.

3. Sandvig AM, Triantafyllidou S, Edwards M, Heumann D, Boyd G, Kirmeyer G. Nonleaded brass-A summary of performance and costs. Journal American Water Works Association. 2009;101(7):83-94.

4. Zeng D, Xiao L, Zhao X, Wang Y. Effect of Chromium on Corrosion Resistance of Aluminum Brass. Materials Protection. 2014;47(12):47-49, 51 .

5. Zhang J, Li Z, Chen C, Tang N, Zhang DZ. Microstructure and properties of aluminum brass with Ce. The Chinese Journal of Nonferrous Metals. 2008;18(11):1989-1994.

6. Garg R, Ranganathan S, Suwas S. Effect of mode of rolling on development of texture and microstructure in two-phase $(\alpha+\beta)$ brass. Materials Science and Engineering: A. 2010;527(1819):4582-4592.

7. Zeng Delu. Research on the corrosion resistance of aluminum brass with trace $\mathrm{Cr}, \mathrm{Co}[\mathrm{D}]$. ChangSha: Central South University; 2014.
8. Qi JG, Wang JZ, He LJ, Zhao ZF, Du HL. An investigation for structure transformation in electric pulse modified liquid aluminum. Physica B: Condensed Matter. 2011;406(4):846-849.

9. Du HL, Wang JZ, Wang B, Cang D. Preparation of cobalt oxalate powders with the presence of a pulsed electromagnetic field. Powder Technology. 2010;199(2):149-153.

10. Qi JG, Wang JZ, Du HL, Cao LY. Heredity of Aluminum Melt by Electric Pulse Modification. Journal of Iron and Steel Research, International. 2007;14(5):76-78.

11. Qi JG, Wang JZ, Wang B, Cang D. Viscosity of liquid aluminum modified by electric pulse. International Journal of Modern Physics B. 2009;23(6-7):869-874.

12. Qi JG, Zhao ZF, Dai S, Zhang DJ, Wang JF. Further studies on heredity of liquid aluminum modified by electric pulse. China Foundry. 2011;8(3):321-324.

13. He LJ, Wang JZ, Qi JG, Du HL, Zhao F. Influences of electric pulse on solidification structure of LM-29 Al-Si alloy. China Foundry. 2010;7(2):153-156.

14. Zhao ZF, Qi JG, Wang JZ. Effects of Electric Pulse Treatment on $\gamma$ Phase in Silicon Brass. Foundry Technology. 2013;34(9):1108-1111.

15. Cao CN, Zhang JQ. An Introduction to Electrochemical Impedance Spectroscopy. Beijing: Science Press; 2002.

16. Wu J, Li XG, Dong CF, Zhang SP, Zhou JL. Initial Corrosion Behavior of Copper and Brass in Tropical Maritime Atmospheric Environment. Journal of Chinese Society for Corrosion and Protection. 2012;32(1):70-74.

17. Liao XN, Cao FH, Zheng L, Liu WJ, Chen A, Zhang JQ, et al. Corrosion behaviour of copper under chloride-containing thin electrolyte layer. Corrosion Science. 2011;53(10):3289-3298.

18. Tahara A, Shinohara T. Influence of the alloy element on corrosion morphology of the low alloy steels exposed to the atmospheric environments. Corrosion Science. 2005;47(10):2589-2598.

19. Wang JH, Jiang XX, Li SZ. Advances of researches on the dezincification mechanism of brass. Chinese Journal of Materials Research. 1999;13(1):1-8.

20. Jiang MJ, Guo XC, Yang J. The Characteristics and Protective Methods of Brass Dezincification Corrosion. Journal of Logistical Engineering University. 2008;24(4):35-38.

21. Zhao Z. Research on Solidification Microstructures, Properties and Mechanism of Brass Alloy under Electric Pulse Treatment. [Dissertation]. Beijing: University of Science and Technology Beijing; 2015. 